УДК 378.018.43:004.9:517

DOI https://doi.org/10.26661/2522-4360-2021-2-43

\title{
СТВОРЕННЯ ЕЛЕКТРОННИХ ДОДАТКІВ ДО ЗАНЯТЬ У ЗАКЛАДАХ ВИЩОЇ ОСВІТИ 3 ВИКОРИСТАННЯМ ОНЛАЙН-СЕРВІСІВ
}

\author{
Тітова О. О. \\ кандидат технічних наук, доцент, \\ доиент кафедри фундаментальної математики \\ Запорізький національний університет \\ вул. Жуковського, 66, Запоріжжя, Україна \\ orcid.org/0000-0001-8471-0867 \\ toa7676@gmail.com
}

Ключові слова: комп 'ютерні технології, онлайн-вправи, математичні вправи, дистаниійне навчання, LearningApps, Wordwall.
Стаття звернена до проблеми сучасної організації навчального процесу у вищих навчальних закладах України в умовах як очного навчання, так і дистанційних форм навчання без втрат у змісті навчального процесу. Одним із напрямків підвищення якості математичної освіти під час дистанційного та змішаного навчання $є$ використання нових підходів та методів навчання, які впроваджуються в тісній взаємодії 3 новітніми інформаційними технологіями. Сучасний швидкий розвиток інформаційно-комунікаційних технологій надає викладачам унікальну можливість розширити свій арсенал методів, форм та засобів викладання, використовуваних у педагогіці. Підвищення мотивації студентів, використання сучасних засобів у рамках освітнього процесу дозволяє підвищити якість навчання, формувати необхідні компетентності. Доведено, що інтерактивні технології навчання мають великий освітній і розвивальний потенціал, забезпечують максимальну активність учасників освітнього процесу, оптимальний час навчання і його результативність. У статті розглядаються особливості створення і використання електронних додатків до занять. Проаналізовано дослідження багатьох авторів щодо навчання 3 використанням комп'ютерних технологій та сутність інноваційних освітніх технологій. Розглянуто можливості використання різних онлайн-інструментів та ресурсів, які дозволяють організувати співпрацю під час навчального процесу. Здійснено огляд інструментів для створення електронних додатків, наведено деякі алгоритми їх використання, підготовлено приклади їх застосування на різних етапах навчального процесу. Продемонстровано основні переваги використання описаних сервісів. Запропоновано тренувальні онлайн-вправи (для ознайомлення 3 новим матеріалом, для закріплення, для контролю знань та інші) з математичного аналізу та інших дисциплін, створені за допомогою таких сервісів, як LearningApps, Wordwall. Результати дослідження свідчать про те, що Інтернет-ресурси та сучасні інформаційні технології значно розширюють потенціал навчального матеріалу, сприяють розвитку рівня мотивації студентів та диференціації методів, форм і засобів навчання математиці з урахуванням індивідуальних особливостей студентів. 


\title{
CREATION OF ELECTRONIC APPENDICES TO CLASSES IN HIGHER EDUCATION INSTITUTIONS USING ONLINE SERVICES
}

\author{
Titova O. O. \\ Candidate of Technical Sciences, Associate Professor, \\ Associate Professor at the Department of Fundamental Mathematics \\ Zaporizhzhia National University \\ Zhukovskoho str., 66, Zaporizhzhia, Ukraine \\ orcid.org/0000-0001-8471-0867 \\ toa7676@gmail.com
}

Key words: комп 'ютерні технологіi, online exercises, mathematical exercises, distance learning, LearningApps, Wordwall.
The paper addresses the problem of organization of educational process in higher educational institutions of Ukraine under for full-time education as well as for distance form of learning without loss in the content of the educational process. One of the directions for improving the quality of mathematics education during distance and blended learning is the use of new approaches and teaching methods, which are implemented in close interaction with the latest information technologies. Modern rapid development of information and communication technologies gives teachers a unique opportunity to expand their arsenal of methods, forms and means of teaching, used in pedagogy. Increasing the motivation of students, the use of modern tools in the educational process, can improve the quality of education, develop the necessary competencies. It is proved that interactive learning technologies have great educational and developmental potential, provide maximum activity of the participants in the educational process, optimal training time and its effectiveness. The article considers the special aspects of creating and using electronic applications for classes. The researches of many authors on computer-assisted learning and the essence of innovative educational technologies are analyzed. Possibilities of using various online tools and resources that allow organizing cooperation during the learning process are considered. The tools for created electronic appendices are reviewed, some algorithms for their application are given and examples of their application for any stage of the educational process are prepared. The main advantages of using the described services are demonstrated. We offer online training exercises (to get acquainted with new material, to consolidate, to control knowledge, etc.) in mathematical analysis and other disciplines, created using services such as LearningApps, Wordwall. The results of the study show that Internet resources and modern information technologies significantly expand the potential of educational material, contribute to the development of student motivation and differentiation of methods, forms and means of learning of mathematics, taking into account the individual characteristics of students.
Завданнями сучасної освіти, зокрема математичної, педагогічної, є навчити людину навчатися та обучити ефективній взаємодії в процесі навчальної діяльності, тобто формувати здатність цілеспрямовано оволодівати професійними навичками, розвивати вміння комунікувати, знаходити та опрацьовувати дані, проявляти свій творчий потенціал, знайти шлях до самовираження та реалізації себе в житті. Одна з основних проблем сучасної дидактики полягає у виборі оптимального співвідношення найкращих традицій чинної освітньої системи, інструментарію інформаційно-комунікаційних технологій, сучасних педагогічних інновацій та тенденцій. Потребою сьогодення $є$ проблема пошуку ефективних освітніх технологій, що здатні допомогти у вирішенні даної проблеми.

Розв’ язанню цих завдань сприяє впровадження в освітній процес сучасних інтерактивних засобів навчання. Використання інтерактивних засобів дає змогу ефективно реалізувати ідеї змішаного навчання («blended learning») як найбільш перспективного підходу до організації навчання в сучасній освітній практиці багатьох країн. 
Розробка навчальних програм, що передбачають застосування системи інтерактивних засобів навчання, оптимізує перехід від предметного принципу побудови змісту освіти до компетентнісної орієнтації навчальних курсів.

Аналіз сучасних досліджень свідчить, що проблемі впровадження інтерактивних технологій навчання присвячено статті та посібники багатьох авторів, зокрема Гладун М., Сабліної М., Гуревич Р., Шестопалюк О., Коношевського О., Демида Б., Копил I., Сагайдак С., Думанської Т., Жарких Ю., Лисоченко С., Сусь Б., Третяк О., Ковтонюк Г. [1-8]. Дослідження стосовно викладання математики та інформатики 3 використанням сучасних інформаційно-комунікаційних технологій в умовах сьогодення обговорюються на науково-практичних конференціях [10-12]. У роботі [4], наприклад, говориться, що «з розвитком інформаційних технологій перед суспільством постала важлива проблема, яка полягає у створенні перспективної нової системи освіти, яка має підготувати суспільство до життя в нових умовах цивілізації. Цим пояснюється виникнення нової форми навчання - дистанційної, поряд із формами вже відомими і традиційними - стаціонарною, заочною, екстернатом тощо». Однак саме зараз жодна із традиційних форм навчання не може бути повноцінно реалізована без використання дистанційної взаємодії із застосуванням сучасних онлайн-сервісів.

Мета даного дослідження - проаналізувати особливості застосування електронних додатків та обгрунтувати ефективність використання сучасних онлайн сервісів ід час вивчення математичних дисциплін студентами вищих навчальних закладів освіти.

Існує велика кількість онлайн-інструментів для забезпечення взаємодії учасників навчального процесу, створення цікавих дидактичних матеріалів (вправ) з будь-якої теми з використанням текстів, формул, зображень, відео- та аудіофайлів у тому числі інтерактивних [2; $3 ; 9]$. Вони дають можливість вбудувати створені вправи на сторінці курсу в системі moodle, у блозі, в соціальних мережах тощо. Застосування деяких із них розглянемо, проаналізуємо, використаємо під час проведення занять.

Серед усього різноманіття онлайн-інструментів, які можна використовувати з будь-якого гаджету, підключеного до мережі Інтернет під час занять, самостійної роботи та для підвищення мотивації до навчання, виокремимо сервіс LearningApps (http://learningapps.org) та сервіс Wordwall (https:// wordwall.net). Ці хмарні сервіси $є$ платформами для підтримки процесів навчання та викладання за допомогою невеликих інтерактивних модулів, $€$ міжнародними, мають можливість використову- вати українську мову. Створені за допомогою них інтерактивні модулі можуть використовуватись безпосередньо як навчальні ресурси або для самостійної роботи. Таким чином, до будь-якого курсу можна розробити загальнодоступну бібліотеку незалежних блоків, придатних для повторного використання та змін. Блоки (вони називаються Вправами) не включені в жодні конкретні сценаpiï чи програми, тому вони не розглядаються як цілісні заняття, натомість їх можна використати в будь-якому доречному методичному сценарії (під час проведення занять у вигляді інтерактиву, на позааудиторних заходах, для проведення квестів та ігор, як наочний матеріал під час вивчення нового матеріалу або для його закріплення та як контрольно-перевірочний матеріал після вивчення будьякої теми). Частину вправ (наприклад, «Скачки» в LearningApps, «Ігрова вікторина» в Wordwall) студенти можуть виконувати, об'єднуючись у групи, та змагатися за право першими прийти до фінішу, вирішуючи поставлені завдання.

Наведемо алгоритми створення дидактичних матеріалів за допомогою цих онлайн-сервісів. Для створення інтерактивної вправи за допомогою сервісу LearningApps можна використати такий алгоритм:

Крок 1. Запускаємо програму за посиланням https://learningapps.org.

Крок 2. Вибираємо вкладку Створення вправи.

Крок 3. Вибираємо тип вправи. У кожній групі доступно кілька шаблонів вправ, опис та зразки яких можна попередньо переглядати перед тим, як створити власний навчальний ресурс.

Крок 4. Вибираємо Створити нову вправу.

Крок 5. Заповнюємо відповідні поля (тип вправи, відповідні до типу матеріали).

Крок 6. Вибираємо Завершити редагування та переглянути вправу.

Крок 7. Переглядаємо вправу і при потребі редагуємо.

Крок 8. Вибираємо Зберегти вправу. Якщо не створено облікового запису (не зареєстровані), то слід створити обліковий запис. До вправи завжди можна перейти за посиланням, яке з'явиться на екрані, також вправу завжди можна буде відредагувати. Посилання бажано зберегти в окремому файлі, до якого можна буде звернутись у подальшій роботі.

Для створення інтерактивної вправи за допомогою сервісу Wordwall можна використати такий алгоритм:

Крок 1. Запускаємо програму за посиланням https://wordwall.net/uk.

Крок 2. Вибираємо вкладку Функиії.

Крок 3. Вибираємо вкладку Створити Вправу.

Крок 4. Вибираємо шаблон вправи. Шаблони включають знайомі класичні формати, як-от 
вікторина і кросворд. На сервісі також є аркадні ігри, наприклад погоня в лабіринті і літак, та інші інструменти.

Крок 5. Вводимо вміст вправи (заповнюємо відповідні поля).

Крок 6. Вибираємо Готово (грати).

Крок 7. Переглядаємо вправу і при потребі редагуємо.

Крок 8. Вибираємо Поділитися, обираємо потрібне (наприклад, зробити загальнодоступним, щоб одержати посилання). Одержали посилання на створений ресурс.

Розглянуті сервіси надають велику бібліотеку вправ стосовно шкільних курсів. На жаль, зараз кількість вправ, які можна використати у вивченні математичних дисциплін у вищих навчальних закладах, не така велика, їх створення потребує часу i подолання певних труднощів (специфіка набору складних математичних текстів, формул, багатовимірних графіків, великі обсяги інформації тощо).

Наведемо приклади використання створених інтерактивних вправ під час вивчення дисципліни «Математичний аналіз» студентами першого курсу математичного факультету спеціальностей 122 Комп'ютерні науки та 014 - Середня освіта (Математика, Інформатика, Фізика).

Під час вивчення нового матеріалу можна використати вправи «Аудіо- та відео-контент», «Пазл», «Вгадай слово», «Фрагменти зображення» y LearningApps, «Відкрийте вікно», «Анаграма» у Wordwall.

На етапі закріплення матеріалу зручними можуть виявитись такі вправи: «Знайти пару», «Класифікація», «Заповнити пропуски», «Заповнити таблицю», «Просте упорядкування» у LearningApps, «Правильно, неправильно», «Відповідники», «Відсутнє слово», «Наведіть порядок» у Wordwall.

Для самостійної роботи можна пропонувати такі вправи, як: «Пазл», «Кросворд», «Знайти слова», «Перший мільйон», «Вікторина» у LearningApps, «Кросворд», «Пошук слів», «Вікторина» у Wordwall.

Для роботи у групах зручно використати вправи: «Скачки», «Порахувати», у LearningApps,
«Ггрова вікторина», «Погоня в лабіринті» y Wordwall.

Під час повторення та узагальнення матеріалу можна використати вправи «Таблиця відповідностей», «Класифікація», «Заповнити пропуски» у LearningApps, «Сортування за групами», «Відсутнє слово» у Wordwall.

Посилання на вправи було надано студентам на сторінках курсу в системі moodle. Наведемо деякі 3 них: https://learningapps.org/watch? $\mathrm{v}=\mathrm{ps} 2 \mathrm{khficj} 21$; https://learningapps.org/watch? $\mathrm{v}=$ pfi7 $7 \mathrm{xtb} 0 \mathrm{n} 21$; https://learningapps.org/watch? $\mathrm{v}=\mathrm{p} 1 \mathrm{y} 730 \mathrm{fkt} 21$; https://learningapps.org/watch? $\mathrm{v}=$ pri534nuc21; https://learningapps.org/watch? $\mathrm{v}=$ pgnigv $4 \mathrm{gc} 21$; https://learningapps.org/watch? $\mathrm{v}=\mathrm{p} 0 \mathrm{mqnd} 04 \mathrm{j} 21$; https://learningapps.org/watch? $\mathrm{v}=$ pmpm5ev1a21.

Зауважимо, що вибір типу вправи, її змістовне наповнення - це творчий процес. Розглянуті онлайн-сервіси дають змогу викладачеві видозмінювати та удосконалювати наявні вправи, що робить їх зручним інструментом для створення електронних додатків до занять.

Висновки. До основних умов ефективної організації навчального процесу слід віднести необхідність забезпечення постійного спілкування усіх учасників, свідомої творчої взаємозалежності, активної особистої участі в роботі, формування навичок роботі в команді з метою підвищення іiі ефективності. Онлайн-ресурси дозволяють урізноманітнювати навчальний процес, підсилити мотивацію. Переваги інтерактивних дидактичних матеріалів перед традиційними полягають у їхній наочності, доступності, креативності, в застосуванні комп’ютера та гаджетів, у використанні різних типів файлів (аудіо, відео, графічні та ін.), а також різних типів вправ, що сприяє розвитку інтересу, пізнавальної активності. Переваги онлайн-сервісів вказують на доцільність їх використання у процесі підготовки інтерактивного дидактичного матеріалу для студентів, публікації та обговорення створених вправ, при цьому викладачі та студенти розвивають критичне та творче мислення, формують комунікативні навички та навички роботи з інформаційно-комунікаційними технологіями.

\section{ЛІТЕРАТУРА}

1. Гладун М.А., Сабліна М.А. Сучасні онлайн інструменти інтерактивного навчання як технологія співробітництва. Open educational e-environment of modern University. 2018. № 4. С. 33-43.

2. Гуревич Р.С., Шестопалюк О.В., Коношевський Л.Л., Коношевський О.Л. Комп'ютерно орієнтовані засоби та мультимедійні технології навчання : навчальний посібник. Вінниця : ТОВ Фірма «Планер», 2012. 619 с.

3. Гуржій А.М., Гуревич Р.С., Коношевський Л.Л., Коношевський О.Л. Мультимедійні технології та засоби навчання : навчальний посібник / за ред. академіка НАПН України Гуржія А.М. Вінниця : Нілан-ЛТД, 2017. 556 с.

4. Демида Б., Копил І., Сагайдак С. Системи дистанційного навчання: огляд, аналіз, вибір. Вісник Національного університету «Львівська політехніка». Комп'ютерні науки та інформаційні технологіï. 2011. № 694. С. 98-107. 
5. Думанська Т.В. Онлайн-сервіси для дистанційного навчання математики студентів вишів: переваги і недоліки. Фізико-математична освіта. 2020. Випуск 3(25). Частина 1. С. 44-48.

6. Жарких Ю.С., Лисоченко С.В., Сусь Б.Б., Третяк О.В. Комп’ютерні технології в освіті : навчальний посібник. Київ : Видавничо-поліграфічний центр «Київський університет», 2012. 239 с.

7. Ковтонюк Г.М. Деякі аспекти використання хмарних сервісів у підготовці майбутніх учителів. Сучасні інформаційні технології та інноваційні методики навчання у підготовщі фахівиів: методологія, теорія, досвід, проблеми. 2014. Випуск 38. С. 315-319.

8. Коношевський О.Л. Формування професійної компетентності майбутнього вчителя в інформаційному освітньому середовищі. Сучасні інформаційні технології та інноваційні методики навчання в підготовиі фахівиів: методологія, теорія, досвід, проблеми. 2011. Випуск 28. С. 353-359.

9. Сервіси для створення дидактичних матеріалів. URL : http://ow.ly/ZS5x9.

10. Chemerys O. Computer technologies in teaching linear algebra. III Міжнародна науково-практична Інтернет-конференція «Математика та інформатика у вищій школі: виклики сучасності»: збірник тез. Вінниця. 2021. С. 194-197. URL : https://drive.google.com/file/d/1PXYe7jHxO6gohPLWHaI57WCxX5wzd19/view? usp=sharing.

11. Mamon O. Conditions for effective using of mobile technologies in general secondary education institutions. III Міжнародна науково-практична Інтернет-конференція «Математика та інформатика у вищій школі: виклики сучасності»: збірник тез. Вінниця. 2021. C. 225-227. URL : https://drive.google.com/file/d/1PXYe7jHxO6gohPLWHaI57WCxX-5wzd19/view?usp=sharing.

12. Titova $\mathrm{O}$. Use of online services in the study of mathematical analysis during distance learning. III Міжнародна науково-практична Інтернет-конференція «Математика та інформатика у вищій школі: виклики сучасності»: збірник тез. Вінниця. 2021. С. 250-251. URL : https://drive.google.com/ file/d/1PXYe7jHxO6gohPLWHaI57WCxX-5wzd19/view?usp=sharing.

\section{REFERENCES}

1. Gladun M., Sablina M. (2018) Suchasni onlayn instrumenty interaktyvnoho navchannya yak tekhnolohiya spivrobitnytstva. Open educational e-environment of modern University. vol. 4. pp. 33-43.

2. Hurevych R. S., Shestopalyuk O. V., Konoshevskyi L. L., Konoshevskyi O. L. (2012) Kompyuterno oriyentovani zasoby ta multymediyni tekhnolohiyi navchannya : navchalnyy posibnyk. Vinnytsia : TOV Firma «Planer», $619 \mathrm{p}$.

3. Hurzhiy A. M., Hurevych R. S., Konoshevskyi L. L., Konoshevskyi O. L. (2017) Multymediyni tekhnolohiyi ta zasoby navchannya : navchalnyy posibnyk / za red. akademika NAPN Ukrayiny Hurzhiya A. M. Vinnytsia : Nilan-LTD, $556 \mathrm{p}$.

4. Demyda B., Kopyl I., Sahaidak S. (2011) Systemy dystantsiinoho navchannia: ohliad, analiz, vybir. Visnyk Natsionalnoho universytetu "Lvivska politekhnika". Kompiuterni nauky ta informatsiini tekhnolohii. Vol. 694. pp. 98-107.

5. Dumanska T. (2020) Online services for distance learning of mathematics for students of universities: advantages and disadvantages. Physical and Mathematical Education. Issue 3(25). Part 1. pp. 44-48.

6. Zharkikh Yu. S., Lysochenko S. V., Sus B. B., Tretiak O. V. (2012) Kompyuterni tekhnolohiyi v osviti : navchalnyy posibnyk. Kyiv : Vydavnycho-polihrafichnyy tsentr «Kyyivskyi universytet», 239 p.

7. Kovtonyuk G. M. (2014) Deyaki aspekty vykorystannya khmarnykh servisiv u pidhotovtsi maybutnikh uchyteliv. Modern information technologies and innovative methods of training in the specialists' preparation: methodology, theory, experience, problems. vol. 38. pp. 315-319.

8. Konoshevskyi O. L. (2011) Formuvannya profesiynoyi kompetentnosti maybutn'oho vchytelya v informatsiynomu osvitn'omu seredovyshchi. Modern information technologies and innovative methods of training in the specialists 'preparation: methodology, theory, experience, problems. vol. 28. pp. 353-359.

9. Services for creating didactic materials. http://ow.ly/ZS5x9

10. Chemerys O. (2021) Computer technologies in teaching linear algebra. III International Scientific and Practical Internet Conference «Mathematics and Informatics in Higher Education: Challenges of Modernity»: Book of Abstracts. Vinnytsia. pp. 194-197.

11. Mamon O. (2021) Conditions for effective using of mobile technologies in general secondary education institutions. III International Scientific and Practical Internet Conference «Mathematics and Informatics in Higher Education: Challenges of Modernity»: Book of Abstracts. Vinnytsia. pp. 225-227.

12. Titova O. (2021) Use of online services in the study of mathematical analysis during distance learning. III International Scientific and Practical Internet Conference «Mathematics and Informatics in Higher Education: Challenges of Modernity»: Book of Abstracts. Vinnytsia. pp. 250-251. 